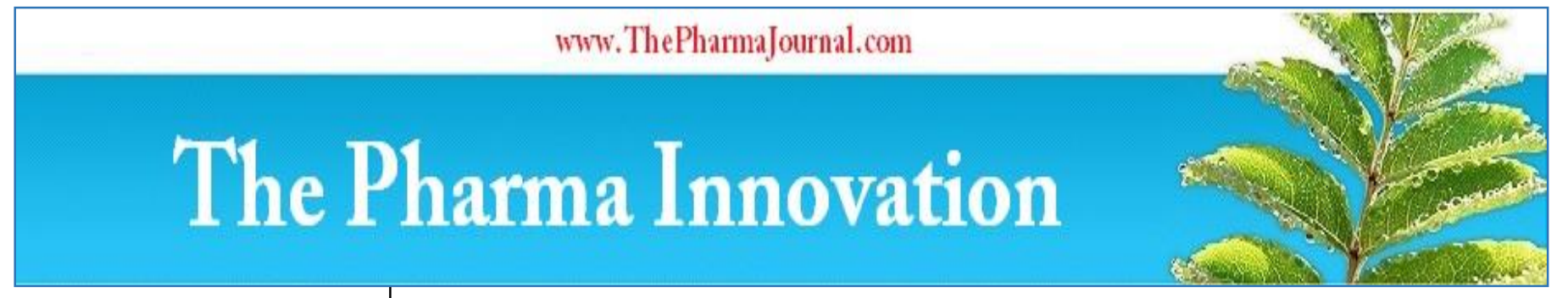

ISSN (E): 2277 - 7695

ISSN (P): 2349-8242

NAAS Rating: 5.23

TPI 2021; 10(5): 182-191

(C) $2021 \mathrm{TPI}$

www.thepharmajournal.com

Received: 14-02-2021

Accepted: 23-03-2021

\section{Rupali Sharma}

Lovely Faculty of Technology

and Sciences, Lovely

Professional University,

Phagwara, Punjab, India

\section{Anjan Borah}

Lovely Faculty of Technology

and Sciences, Lovely

Professional University,

Phagwara, Punjab, India
Corresponding Author: Anjan Borah

Lovely Faculty of Technology

and Sciences, Lovely

Professional University,

Phagwara, Punjab, India

\title{
Prospect of microcapsules as a delivery system in food technology: A review
}

Rupali Sharma and Anjan Borah

DOI: $\underline{\text { https://doi.org/10.22271/tpi.2021.v10.i5c.6195 }}$

Abstract

Microencapsulation is the process by which any active substances are coated with the help of very small capsules. The size of the capsules can range from one micron to several hundred micron values. The usage of these capsules is not limited to any field; it plays important role in many industries related to pharmaceutical, biotechnology, food industries and in research applications as well. With the help of this latest technology encapsulation of vitamins, minerals, phytochemicals, flavors, omega-3 fatty acids, micro-organisms, enzymes, oils, peptides, protein hydrolysate, antioxidants and polyphenols is possible and there are many factors that play a vital role in the efficiency of microcapsules such as the concentration of polymer, rate of solvent removal, solubility of polymer insolvent, etc. microencapsulation can be done in many ways such as; spray drying, extrusion, lyophilization, coacervation, spray cooling, fluidized bed coating, co-crystallization and inclusion complexation. The article is a review of microencapsulation technology and lays emphasis on various substances that can be encapsulated with the help of this technique and different types of microencapsulation.

Keywords: Microencapsulation, substances, technology, types

\section{Introduction}

Microencapsulation is a rapid process widely used in the pharmaceutical or food industries in which every single tiny droplet of solid or liquid material is coated with a continuous film of polymeric material (Suganya \& Anuradha, 2017) ${ }^{[58]}$. The procedure of microencapsulation was introduced by Bungen burg de Jon \& Kan in the year 1931. This process involves the conversion of liquids to solids, so as to alter the colloidal surface properties, protection against environmental factors and control the release characteristics of various coated materials (Bakry et al., 2016) ${ }^{[4]}$. The diameter of microencapsulated product ranges between 1-1000 $\mu \mathrm{m}$ (Paulo $\&$ Santos, 2017) ${ }^{[45]}$. Microcapsules are used for various purposes because they provide a large number of core materials like live cells, adhesives, flavors, agrochemicals, enzymes, pharmaceuticals etc., can be encapsulated (Sulu et al., 2016) ${ }^{[59]}$. This process can be used to increase the stability of compounds, to reduce the undesirable taste and to improve the release of properties of compounds such as essential oils, antioxidants, enzymes etc in food industries (Kilicay et al., 2016) ${ }^{[35]}$. Microencapsulation has proven to be the best way for the incorporation of the natural dyes in the food products and leading to the high stability during the processing and storage (Ribeiro, J. S., \& Veloso, C. M. (2020) ${ }^{[49]}$. The excellent result depends upon the correct choice of the method and material. Microencapsulation is a better way to utilize the food in a best way, so as to increase its nutritional value and make a healthy and more over to increase the stability and bioavailability of food (Peunparkdee et al., 2016) [46]. The wall material, capsules, core release forms, and encapsulation methods play a very important role in this process (Carvalho et al., 2015) ${ }^{[10]}$. The entire result of the process is based upon these relevant aspects.

\section{Capsule}

Mainly capsules are divided into three main categories: Nano capsules $(<0.2 \mu \mathrm{m})$, microcapsules $(0.2$ to $5,000 \mu \mathrm{m})$, macro capsules $(>5,000 \mu \mathrm{m})$. (Wang et al., 2015)

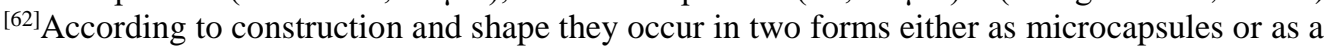
microsphere. Microcapsules cover the active substance with a continuous polymer layer constituting the capsule membrane (Casanova et al., 2016) ${ }^{[11]}$. 


\section{Wall material}

Wall material is responsible for better stability and efficiency (Wazarkar et al., 2016) ${ }^{[64]}$. Excellent wall material should always have these properties: not receive with the core; ability to seal and maintain the core inside the capsule; maximum protection to the core against adverse conditions; masking of bitter or bad taste, so as to increase the food applicability

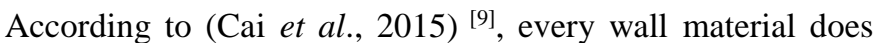
not have all the properties, so for good results the combination of two or more materials is preferred. This material can be extracted from a huge variety of natural or synthetic polymers. Carbohydrates, gums, lipids and inorganic material are the some of the materials for the extraction of polymer.

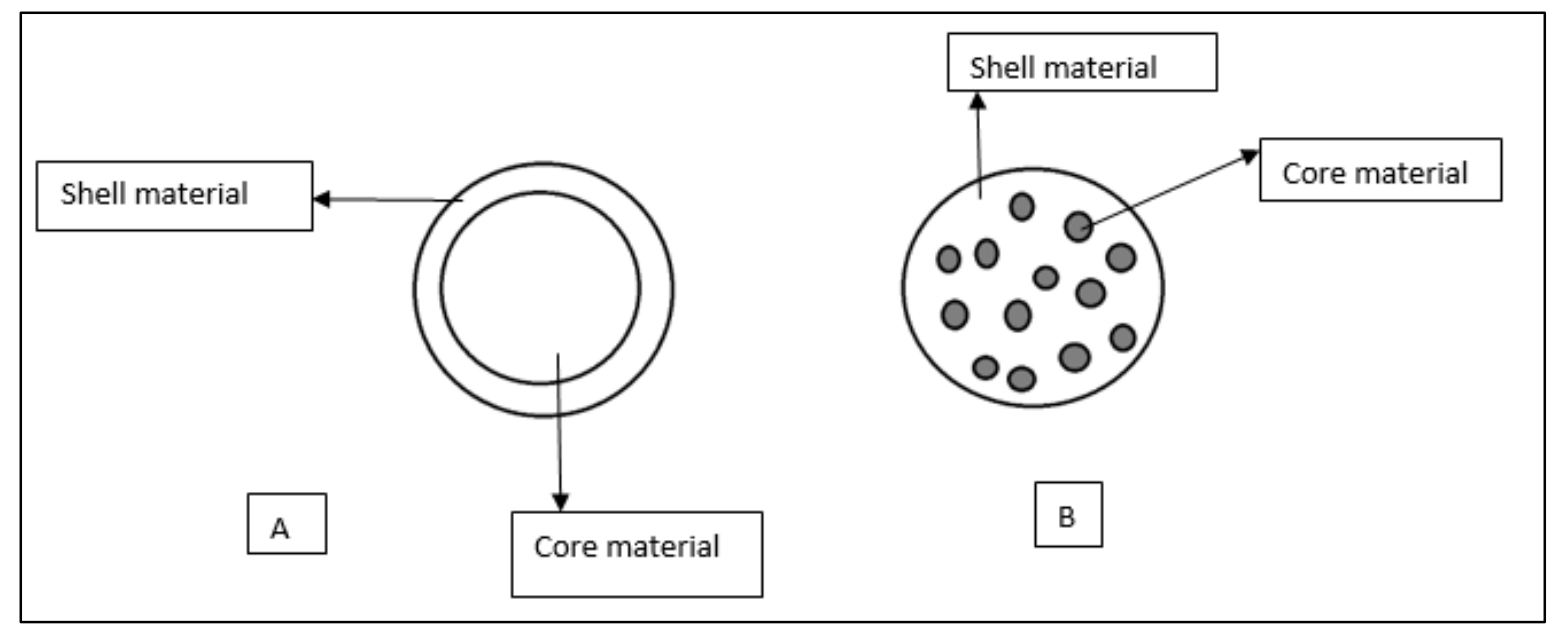

Fig 1: Representations of microcapsules A) Core surrounded by shell B) Core material dispersed in matrix shell

\section{Controlled core release}

Core should be kept away from the external environment till the release is desired. Therefore, proper time and place is important factor for the core release, improving the effectiveness, low dose of additives is required and expanding the applications of compounds of interest. Interaction between the core and wall material has an adverse effect on the releasing rate (Khanbdahale, 2020) ${ }^{[34]}$. Moreover, the particle size, ratio of core and wall material and volatility of core influences the release. The main mechanism involved in the core release: temperature, $\mathrm{pH}$, pressure, solvent, diffusion and degradation or the combination of more than one. Diffusion occurs especially when the microcapsule wall is intact (Timilsena et al., 2019) ${ }^{[60]}$. According to (kumar et al., 2013) [37], degradation release occurs on the degradation of proteins or lipids by the action of enzymes such as proteases and lipases respectively. In contact with a solvent, the wall material dissolves completely, quickly releasing the core or start to expand, resulting in the flavor release. The $\mathrm{pH}$ release occurs when the $\mathrm{pH}$ changes, resulting in the alteration of the wall material solubility, finally leads to core release (Ballesteros et al., 2017) ${ }^{[5]}$. Changes in temperature can promote core release. It has a two ways: temperature-sensitive release (critical temperature is required for expanding and collapsing of material) and fusion-activated release (melting of the wall material along with the rise in temperature).Pressure release occurs when a pressure is applied to the capsule wall (Martin et al., 2015) ${ }^{[40] .}$

\section{Encapsulation Methods}

The selection an appropriate method depends upon the size and shape of particles required, core type, the wall material and the core release. The main encapsulation methods are: Spray drying, spray cooling, extrusion, coacervation, lyophilization and emulsification, gelation, supercritical fluid, polymerization and fluidized bed (Khan et al., 2016) ${ }^{[32]}$.

\section{Spray drying}

This process involves the formation of a solution, emulsion or suspension containing the core and wall material, followed by nebulization in a drying chamber with circulating hot air. With the continuous contact with the hot air, water evaporates instantly and the material encapsulates the core. Choosing atomizer is one of the most important steps when it comes to the processing of designing. Atomization has some advantages over other methods: large equipment availability, wide variety of encapsulating agents can be employed, potentially large-scale production, simple equipment, good efficiency, reduced storage and transport costs and low process cost whereas the production of non-uniformly sized materials is the main disadvantage of atomization.

This technique is used to encapsulate mainly lipids, flavors and pigments. In this method, the use of thermo-sensitive products is very limited, as the required high temperature leads to the destruction or volatilization of the product (Manaf et al., 2015) ${ }^{[1]}$.

\section{Spray cooling}

It is the process to elevate the interest for the automation for various processes that are being conducted in case of microencapsulation. Spray cooling microencapsulation is based on injecting the cool air for the solidification of the product. Micro particles are produced by a mixture containing the wall material and core in droplets. The mixture is nebulized by an atomizer and enters a chamber in which air flows at low temperature. The positives of the process include low droplet impact velocity, there is no temperature exceed, it removes the heat uniformly (Ayoub et al., 2019) ${ }^{[3]}$. The reduction of temperature results in the solidification of the wall material, enabling the core to be encapsulated (Wang et al., 2020) ${ }^{[63]}$. This method is considered as the cheapest method as the low temperature is employed in this method and with a high potential for scale-up. This method is mainly used to encapsulate vitamins and minerals (Zhao et al., 2020) ${ }^{[69]}$.

\section{Extrusion}

This method is based on a polysaccharide gel that immobilizes the core when in contact with a multivalent ion. 
Extrusion involves incorporating the core in a sodium alginate solution, followed by a mixture undergoing drop-wise extrusion via a reduced caliber pipette or syringe into a hardening solution, such as calcium chloride (Bamidele et al., 2020) ${ }^{[6]}$. The main advantage of this process is the very long shelf life of flavor compounds due to the provision of an almost impermeable barrier against oxygen. One of the drawback of this method is the rather large particles formed by extrusion (typically $500-1,000 \mathrm{~mm}$ ), which limit the use in applications where mouth-feels a crucial factor. Additionally, a very limited range of wall materials is available for extrusion encapsulation (Fangmeier et al., 2019) ${ }^{[23]}$.

\section{Coacervation}

Coacervation technique involves the deposition of the polymer around the core by altering the physicochemical characteristics of the medium, such as the temperature, ionic strength, $\mathrm{pH}$ and polarity (Eghbal and Choudary, 2018) ${ }^{[18]}$. It is of two types: simple (single macromolecule is present) and complex (two or more molecules are present). It is typically used to encapsulate flavor oils.

\section{Lyophilization}

Lyophilization is a method involving the dehydration of frozen material under a vacuum sublimation process (Kawasaki et al., 2019). The principle behind freeze drying is sublimation (Do Amaral et al., 2019) ${ }^{[19]}$. Steps in the process include sample preparation, freeze primary drying, secondary drying and final product (Khan et al., 2015) [33], this method improves the quality, as there are no changes associated with the high temperature. It is widely used in essences or flavorings. It is also used to improve stability and long term storage of labile drugs.

Emulsification: In this method, first the core is dispersed in an organic solvent. Then, dispersion is emulsified in the water or oil, which contains an emulsion stabilizer (Bakry et al., 2016) [4]. The organic solvent, is then removed by evaporation under stirring, providing the formation of compact polymer globules in which the core is encapsulated. It is widely used to encapsulate vitamins, minerals, enzymes, etc.

\section{Microencapsulated ingredients}

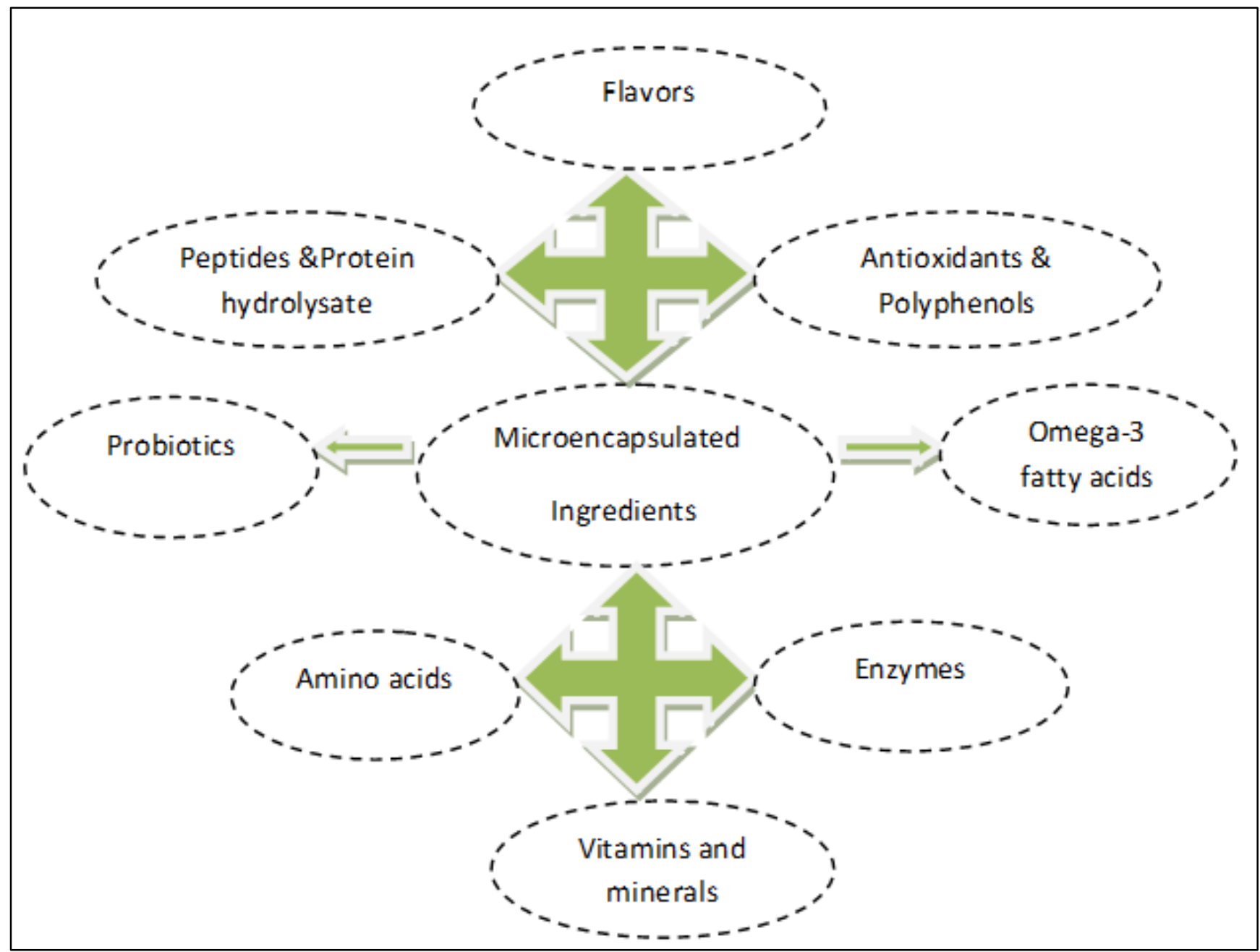

Fig 2: Microencapsulated ingredients

\section{Microencapsulation of natural dyes}

To provide attractive color and increase the demand of the food, the different type of dyes were used. In case of industrial use, there is a need of dyes just in case of loosing color at the time of processing or storage (Codex Alimentarious Commission, 2000: Esquiavel, 2016) ${ }^{[13]}$.

There are different natural dyes, which are responsible for different colors such as; betalains and anthocyanins for red, yellow and purple color (Otalora et al., 2015 \& Rosa et al., 2019) ${ }^{[43]}$, carotenoids for orange and yellow color (Rascon et al., 2011) ${ }^{[48]}$, chlorophylls for green color (Porrarud \& Pranee 2010) ${ }^{[47]}$ and genipin and phycocyanin for blue color (Brauch et al., 2016, Chaiklaban et al., 2012 \& Neri-Numa et al., 2017) ${ }^{[8]}$. 
For industrial use of dyes, the limit has been set, as they are delicate in case of exposure of temperature and oxidation, which is further responsible for the discoloration at the time of processing and storage and even in the reduction of sensory quality of the products (Esquiavel, 2016) ${ }^{[22]}$.

Therefore, to increase the stability of these products encapsulation is necessary. This is widely used for the processing of natural dyes, so as to increase the stability of coating materials by limiting their interactivity with other food constituents and air and also reduces the water activity and effects of high temperature on natural dyes (Jafari, 2017: Rodriguez Amaya, 2016) ${ }^{[30]}$.

Exposure to light, oxygen and high temperature, interactivity with other food constituents hinders the stability of anthocyanins. Although, $\mathrm{pH}$ instability is the extraordinary property, because the $\mathrm{pH}$ difference refers to the structural changes that out-turns to the development of compounds with various colors or even become colorless (Araujo, 2019, Damodaran et al., 2018: Rodriguez-Amaya, 2016: RodriguezAmaya, 2019) ${ }^{[2]}$.

Therefore, studies showed that to increase the stability and the use of natural dyes, microencapsulation has been used. Spray drying is widely used for the microencapsulation of natural dyes (Gaonkar et al., 2014, Ozkan et al., 2019) ${ }^{[26]}$

\section{Polyphenols and Antioxidants}

The emission of rays, environment pollution and by products of chemicals and medicines give rise to free radicals and for the destruction of these free radicals antioxidants are required. Antioxidants are the natural or synthetic substances, which hinders the process of oxidation. Furthermore, antioxidants are addressed as "Free radical scavengers" and this property of antioxidants prevents the damage to the cells (Neha et al., 2019) ${ }^{[41]}$.

Polyphenols are referred to as a class of metabolites that derives from the specialized metabolism of plants. These polyphenols have one or more hydroxyl groups affixed to a benzene ring and play a vital role in the defense mechanism so as to avoid the action of plant abiotic stressors and pathogens (SanMiguel, 2017) ${ }^{[56]}$.

\section{Case studies related to microencapsulation of biotic} compounds- Polyphenols and antioxidant

According to (Isailovic et al., 2012) ${ }^{[29]}$ it was studied that microencapsulation of natural antioxidants in different alginate and inulin system can be extracted from Pterospartum tridentatum. The main focus of this study is totally related to safeguard the natural antioxidants from wild herb Pterospartum tridentatum (aqueous extract) by using the process of microencapsulation with the help of alginate hydro gel micro beads. For the preparation of micro beads, the technique of electrostatic extrusion was used. Two types of micro beads were used, one was plain $\mathrm{Ca}$-alginate and another was $\mathrm{Ca}$-alginate filled with inulin having the concentration of $10 \%$ mass and $20 \%$ mass. Fourier transfer infrared (FTIR) was used to determine the various components of micro bead mixture. By using the Folin-Ciocalteau reagent, TPC was measured and the absorbance was checked after 2 hours at $765 \mathrm{~nm}$. To understand the surface morphology, Scanning electron microscopy (SEM) was done. Along with SEM many other tests were done such as calculation of encapsulation efficiency and determination of free radical-scavenging ability. The result depicted that, the micro beads having $20 \%$ mass of inulin has showed the greater efficiency in the field of antioxidant activity as well as total phenolic content. The mixture of alginate-inulin in the form of micro beads showed the greater efficiency. The filling of inulin leads to the better stability and encapsulation capacity.

(Betz et al., 2012) [7] has experimented on the microencapsulation of extracted antioxidant capacity of Bilberry in whey protein hydro gels. Bilberry is a rich source of anthocyanins, having the high antioxidant capacity. To protect the bioactive compounds, the process of microencapsulation has been considered. By the method of drop-wise emulsion, the whey protein microcapsules along with the bilberry extract has been produced. To monitor the antioxidant capacity of bilberry extract at every step, the Trolox equivalent antioxidant capacity (TEAC) was used. It has been observed that the interaction between the bilberry extract and whey protein was responsible for dropping of antioxidant capacity throughout the process and while using an emulsifier through the process, an anthocyanin was responsible for dropping of antioxidant capacity. At the occurrence of such situations, a transformation of hydrophilic anthocyanins to the oil phase was observed. At last to know the mechanism of microcapsules in GI tract, the microcapsules were explored further with the time-dependent released mechanism as compared to non-encapsulated bilberry-anthocyanins inhibited at $\mathrm{pH}$ 6.8. At the $\mathrm{pH}$ 6.8, there was minimum amount of anthocyanin break-down when the non gelled extract- whey protein mixture depicted a safeguard result of domestic whey protein on incubation. Hence, the outcome of this study was the awareness related to proteinbased microencapsulation and evolution of novel encapsulation techniques.

(Floirendo et al., 2013) has experimented on the investigation of phenolic content and antioxidant capacities of microencapsulated blueberry anthocyanins. Three types of solvents were used- ace tonic, methanolic and ethanolic and with the help of these solvents two samples were prepared; by the process of spray drying and various other tests were also done such as scanning electron microscopy, FRAP assay, Total phenolic content, total monomeric anthocyanin content. According to surface morphology, the microcapsules appeared spherical in structure and have smoother appearance and there was no significant difference between the three solvents. The ethanolic extract of whey protein isolate showed more monomeric ACNs as compared to ace tonic and methanolic extracts. According to the comparative analysis between the two samples, whey protein microcapsules had FRAP value as compared to Gum Arabic microcapsules. The antioxidant capacity of ace tonic solvent was highest followed by ethanolic and methanolic. Thus, it was concluded that the alcoholic extracts were more efficient than ace tonic extracts when referred to antioxidant potential.

(Ersus and Yurdagel., 2006) [21] the study is related to microencapsulation of anthocyanin (pigment) from black carrot by the process of spray drying. The black carrots were collected and maltodextrin MDX 29 (28-31 DE) was used as a carrier spray drying agent, then the ethanolic extract was prepared in order to isolate anthocyanin. Feed mixture was prepared and then it was poured into spray dryer @ $5 \mathrm{ml} / \mathrm{min}$. then the pigment powder was stored in brown bottles. Various tests on the samples was conducted such as -Total anthocyanin content, antioxidant as well as DPPH activity and to study the surface morphology scanning electron microscopy (SEM) was done along with color detection. The result depicted that the microcapsules with the presence of 
maltodextrin appeared smooth. The Brix value of black carrot was analyzed to be $11.90 \pm 0.14$; the $\mathrm{DE}$ value of maltodextrin was directly proportional to hygroscopic moisture of sample. The color detection was carried out for 8 weeks and the testing was done at two temperatures i.e. $4^{\circ} \mathrm{c}$ and $25^{\circ} \mathrm{c}$, at $4^{\circ} \mathrm{c}$ the color of sample did not changed but at $25^{\circ} \mathrm{c}$ it turn to brown. It was conclude that due to higher air inlet temperature there was great loss in anthocyanin and storage at $4^{\circ} \mathrm{c}$ increased the life of anthocyanin three times as compared to the sample stored at $25^{\circ} \mathrm{c}$.

(Desai et al., 2019) ${ }^{[18]}$ studied about the microencapsulation of antioxidant as well as phenolic compounds from green coffee. The decaffeination of ground coffee was done with the help of soxhlet apparatus. Then the slurry was prepared using a rotary evaporator and filtered to get the coffee extract, and microcapsules were prepared with the process of spray drying and were stored at $4^{\circ} \mathrm{c}$. According to proximate analysis of total phenolic content of coffee extract was calculated around $12.78 \pm 2.1 \mathrm{mg} \mathrm{GAEg}{ }^{-1}$. The crude fiber and protein, ash, carbohydrates and calorific value of the extract was also calculated and the micronutrients such as $\mathrm{Fe}, \mathrm{Cu}, \mathrm{Ca}$, etc were also evaluated. The scanning electron microscopy (SEM) and results depicted that they were irregular in shape, had smooth texture but few of the particle showed dents and shrinkage on surface. While as the maltodextrin encapsulated particles have bigger size and were smooth as compared to the particles with green coffee extract. Thus, it was concluded that the particles encapsulated with maltodextrin has smoother surface, were soluble in many $\mathrm{pH}$ solution.

(Wilkowska et al., 2017) [65] the study deals with the antioxidant activity and polyphenols of chokeberry juice as well as wine with the help of microencapsulation. Juice and wine were prepared and then three different types of coatings were used for microcapsules by spray drying. The three coatings used were maltodextrin, Arabic gum, and HP- $\beta$ cyclodextrin. The surface morphology of dried powder was studied with the help of SEM. Further analysis was done with respect to polyphenols (HPLC), total polyphenols, antioxidant capacity, ferric reducing/antioxidant power. The storage stability of microcapsules was also checked. The result depicted that the capsules coated by maltodextrin were little dented and has round outer surface while as the microcapsules of HP-CD appeared to have wrinkle surface whereas the capsules prepared from maltodextrin and gum Arabic showed spherical surfaces. The poly phenolic level of chokeberry juice as well as wine has significant level of polyphenols and anthocyanins. Five poly phenolic compounds were detected from the sample. The storage stability of microcapsules was also checked. The highest loss was in case of juice poly phenols as compared to wine. This revealed that the stability of polyphenols juice was much lower as compared to wine.

(Tuan et al., 2016) ${ }^{[61]}$ started the process of extraction as well as encapsulation of poly phenols from guava leaves. Guava leaves collected and the process of extraction was carried out with the help of hot water bath. Then, with the help of microwave extraction technology phenolic compounds were taken out from the powder of guava leaves. The microcapsules were prepared by mixing the maltodextrin and Arabic gum maltodextrin. The results depicted that microwave extraction was able to release more polyphenols as compared to conventional procedures. The DPPH assay showed that the traditional extraction was lower as compared to novel extraction and butylated hydroxytoluene. The plant cell wall structured was studied with the help of scanning electron microscopy and the comparison between raw sample, control sample and the sample extracted from microwave was conducted. The sample with microwave extraction showed improved extraction efficiency. It was concluded that microwave extraction technology is one of the potent method which enhanced the extraction of polyphenols and flavonoids from guava leaves, the antioxidant capacity was also increased and the microencapsulating agents were also the convenient choice.

(Zanoni et al., 2020) ${ }^{[68]}$ the experiment was done for the encapsulation of polyphenols extracted from red chicory as well as red cabbage by the process of spray drying. Three types of solvent were used for extraction; one was methanolwater based, ethanol-water based and water-water. Then microcapsules were prepared by the process of spray drying and many tests were conducted such as antioxidant capacity was checked, thermal stability was examined, water activity was also checked, SEM was conducted. The results depicted that the highest thermal stability was seen in case of ethanol water-based extract. The best extraction capacity was in case of methanol-water based extract the color properties were not altered upon thermal treatment in fact the retention of polyphenols and antioxidant capacity increased by encapsulation. SEM analysis depicted that red cabbage extract showed the presence of irregular and spherical particles while as in case of the red chicory extract the particles appeared bigger. It was concluded that the extract of red cabbage became unstable when exposed to high temperature and other factors such as $\mathrm{pH}$, pigments; light absorption properties remained unaffected and saved upon microencapsulation.

(Robert et al., 2010) [50] studied about the encapsulation of polyphenols and anthocyanins from pomegranate by the process of spray drying. The juice as well as ethanol extract of pomegranate were encapsulated by the help of maltodextrin and soybean protein isolates using spray drying. The microcapsules were analyzed for a period of 56 days, kept in oven at $60^{\circ} \mathrm{c}$. The comparative analysis depicted that polyphenol encapsulation was better in case of soybean protein isolate while in case of anthocyanin better result was seen in case of maltodextrin. The protective effect was more in case of maltodextrin as compared to soybean protein isolate. The addition of yoghurt lead to no significant change in the stability of bioactive compounds, but certain changes were seen in case of encapsulation done by maltodextrin for the ethanol extract of pomegranate.

(Robert et al., 2015) ${ }^{[51]}$ conducted his experiment on purple cactus pear pulp and the encapsulation agents used were polysaccharide protein. There different type of encapsulating agents were used; soybean protein isolate, soybean protein isolate along with maltodextrin and soybean protein isolate with insulin and in all the three cactus pear pulp was encapsulated. Total polyphenols, beta and betaxanthin contents were evaluated. All the study was carried out in dark at $60^{\circ} \mathrm{c}$. During the storage it was seen that there is inverse relation between polyphenols and betalains. The pigments were compared and yellow pigment (betaxanthin) was more stable as compared to red pigment (betacyanin) 
Table 1: Encapsulation of biotic compounds

\begin{tabular}{|c|c|c|c|c|}
\hline S.NO. & Method & Encapsulated Compound & Source & References \\
\hline 1 & Electrostatic extrusion & Natural antioxidants & Pterospartum tridentatum & Isailovic et al., 2012 \\
\hline 2 & Drop-wise extrusion & Antioxidant (anthocyanin) & Bilberry & Betz et al., 2012 \\
\hline 3 & Spray drying & $\begin{array}{c}\text { Phenolic content and antioxidant } \\
\text { (anthocyanin) }\end{array}$ & Bluberry & Floirendo et al., 2013 \\
\hline 4 & Spray drying & Anthocyanin pigment & Black carrot & Ersus \& Yurdugal, 2006 \\
\hline 5 & Spray drying & $\begin{array}{c}\text { Antioxidant as well as phenolic } \\
\text { compounds }\end{array}$ & Green coffee & Dessai et al., 2019 \\
\hline 6 & Spray drying & Antioxidant \& polyphenols & chokeberry & Wilkwska et al., 2017 \\
\hline 7 & Microwave extraction \& traditional extraction & Polyphenols & Guava leaves & Tuan et al., 2016 \\
\hline 8 & Spray drying & Polyphenols & $\begin{array}{c}\text { Red chicory as well as red } \\
\text { cabbage }\end{array}$ & Zamoni et al., 2020 \\
\hline 9 & Spray drying & Polyphenols \& anthocyanins & Pomegranate & Robert et al., 2010 \\
\hline 10 & Spray drying & Polyphenols, betalains, betaxanthin & Purple cactus pear pulp & Robert et al., 2015 \\
\hline
\end{tabular}

\section{Vitamins and minerals}

Vitamins are naturally occurring organic substances which are required by the body in the small amount for the usual growth and metabolism (Wilson and Shah, 2007) ${ }^{[66]}$.

Minerals are naturally occurring inorganic substances having a constant structure, which provides the accurate amount of nutrition to the animal, plant and human body (Li et al., 2014) [38].

\section{Case studies based on encapsulation of vitamins and minerals}

(Ciapara et al., 2004) the study is related to microencapsulation of astaxanthin in the matrix made up of chitosan. Astaxanthin and chitosan were collected and microencapsulation of astaxanthin was done by multiple emulsion or solvent evaporation technique, by the process of cross-linking. Astaxanthin was encapsulated in chitosan based matrix and was stored in the form of duplicates at hree different temperatures- $25^{\circ} \mathrm{C}, 35^{\circ} \mathrm{C}$ and $45^{\circ} \mathrm{c}$ for 8 weeks. HPLC of microcapsules extraction was done, which depicted the separation of astaxanthin isomers before microcapsules and after storage the stability was also checked and retention time peaks for both were also calculated. Thus, it was concluded that it did not prove to be effective method for total pigment extraction from the microcapsules.

(Gadkari and balaraman, 2015) ${ }^{[25]}$ the study deals with the process of extraction and encapsulation of catechins. Raw material was collected in the form of leaves, fruits or fruit skin. Then the process of pretreatment was conducted using drying, grinding and sieving and extraction was carried along with filtration and centrifugation. The concentrate made with the help of rotary evaporator, spray drier or freeze drier. Then they formed concentrate was dissolved in solution of aqueous coating. After this dehydration of homogenized aqueous media was done with the help of super critical mediated process, spray drying or fluidized bed spray method. By the end of this step, catechins were encapsulated. Then it was concluded that leaves were the potent source of catechins among all the other material. They were very unstable with reference to slightest change in $\mathrm{pH}$, temperature and light. Some non standardized processes results in the mortification of catechins from the plant source. Due to the reason, many new processes were developed such as super critical $\mathrm{CO} 2$ extraction. It is considered as one of the best method due to its advantages such as the nontoxic level of solvent, the structural integrity and higher efficiency of the extract.

\section{Flavors}

Flavor is responsible for the taste of the food, which either elevates or modifies the taste (Zhu et al., 2012) ${ }^{[70] .}$

\section{Case studies based on encapsulation of flavors}

(Koupantsis et al., 2014) [36] the study is related to the encapsulation of flavor in milk protein. The microcapsules were prepared which contains beta-pinene by the coacervation of milk protein. Then the droplet size was measured, measurement of proteins and polysaccharide electric potential was also done, GC-FID analysis was conducted. The extraction of encapsulated beta-pinene was also done, $\mathrm{pH}$ was also measured and the result depicted that when the $\mathrm{pH}$ was acidic i.e. 2.8, then there was formation of coacervate type complexes, that worked as the encapsulated agents, the increase in protein/polysaccharide ratio, resulted in changed microcapsule morphology due to which the beta-pinene droplets were immobilized and due to this immobilization there was interaction between non-absorbed proteins and polysaccharides molecules.

\section{Omega-3 fatty acids}

Omega-3 fatty acids are considered as essential fatty acids which are the type of poly -unsaturated fat, acquired from the food sources as the human body is not capable to form them (Czyz et al., 2016) ${ }^{[15]}$.

\section{Case studies related to encapsulation of omega-3 fatty} acids.

(Goyal et al., 2016) ${ }^{[27]}$ the study is related to fortification of dahi (Indian yoghurt) along with Omega-3 fatty acids by microencapsulated flaxseed oil microcapsules. Four different types of formulations of microcapsules flaxseed oil powder were chosen and all the result was depicted on the basis on sensory, one was taken as control and rests three were $1 \%$, $2 \%$ and $3 \%$. As soon as the microcapsules were formulated many parameters were checked such as titrable acidity, oxidative stability and storage conditions were also monitored with the help of Gas liquid chromatography (GLC). As the storage of the fortified samples was done for 12 days, the comparison between the control and other samples were done. It was seen that samples were bit more acidic as compare to control and in case of texture, the value of firmness lied between $2.09-2.14 \mathrm{~N}$ and in control it was $0.88-1.7 \mathrm{~N}$. The firmness was highest in case of control. There was no difference in the peroxide value of fortified dahi and control sample while as in case of $\alpha$-linolenic acid it was seen that there was no change for $1^{\text {st }}$ nine days but after 15 days the value decreased from 1.92-1.68. Thus, it was concluded that it was a patent functional food and could be a great source of attraction for consumers. 


\section{Probiotics}

Probiotics are the live microorganisms, which are safe for the human consumption as they increase the number of good bacteria in the gut (Cook et al., 2012) ${ }^{[14]}$.

\section{Case studies related to encapsulation of micro-organisms (Probiotics).}

(Keen et al., 2012) ${ }^{[31]}$ the study is related to the encapsulation of lactic acid bacteria in Colloidosomes. Microorganisms are selected and colloidosomes were prepared with the help of sunflower oil, sodium chloride, water and ethanol. Various tests were conducted such as- Scanning electron microscopy, cell viability test, glucose trends along with $\mathrm{pH}$ trends were checked. The results depicted that, by green fluorescence the bacteria were seen with the microscopy imaging. Bacteria, which were encapsulated were able to metabolize glucose and were able to produce lactic acid. Most of the colloidosomes appeared spherical and intact. It was also observed that at $\mathrm{pH}$ 3 , there was mild disorganization in the shell of colloidosomes, they also appeared stuck. Thus, it was concluded according to the comparison made between encapsulated and unencapsulated, the viability was more in case of encapsulated bacteria as compared to unencapsulated at $\mathrm{pH} 3$ for 2 hours.

(Chen and Chen 2009) [12], the study is related to the formation of encapsulating material by gellan gum which is a microbial polysaccharide originated from pseudomonas elodea. It is made up of four monomers i.e. glucose, glucoronic acid, glucose and rhamnose. The result concluded that, it is one of the best ways to induce a thermo reversible gelation on cooling of gellan gum solutions and the factors on which gelation temperature depends is polymer concentration, type of counter ions present in the medium and ionic strength. (Livney 2010) ${ }^{[39]}$, the study is related to the formation of encapsulating material by milk proteins as they have potent physical and chemical properties when compared to other proteins. In proper conditions, milk proteins can form gels as gelatin. They are considered as legitimate carrier of probiotic cells due to the properties i.e. physical, chemical and structural. Due to their significant gel formation properties they act as one of the most stable material for encapsulation of probiotic cells and the results also depicted that due to its properties it is one of the most favorable method considered for encapsulation of probiotics.

\section{Enzymes}

Enzymes are the biocatalysts, which accelerates the biochemical reactions in living organisms and one can be taken out from the cells so as to catalyze a number operations (Robinson, 2015) ${ }^{[52]}$.

\section{Case studies related to encapsulation of enzymes}

(Dror et al., 2008) [20] conducted his experiment on encapsulation of enzymes in biodegradable tubular strutine. The polymer, solvent, shell-core solutions and E.coli were collected. Then the enzymes were encapsulated in micro tubes made up of coelectrospinning. The technique of coelectrospinning was used because it has capacity to separate two phases, which can cause harm to enzyme activity. The shell used in this experiment was made up of polycaprolactone (PCL) and dimethylformamide. Due to the separation, it was possible to pressure the enzymatic activity of two enzymes before and after coelectrospinning, which worked only when the fiber mats were kept in an aqueous assay environment. The shell structure was changed by mixing polyacaprolactone along with polyethylene glycol. The mixture resulted in formation of pores in the shells, due to which the movement of the particles inside-out of fibers were affected. Then an enzyme that weighed around 80kda, along with alkaline phosphate was poured through the pores into the broadening medium. The fiber became the release device and one larger enzyme. $\beta$-galactosidase did not drain out of the fiber and remained intact. It was concluded with the help of enzyme assay that the substrates of both the enzymes were diffused property into the fiber and only got cleaved by encapsulated enzyme, which resulted in the diffusion of the product outside the fiber. Among both the enzymes encapsulated it was seen that in case of $\beta$-galactosidase, fiber acted as a potent and stable enzymatic micro reactor.

\section{Peptides and protein hydrolysates}

A peptide is a linkage of two or more amino acids which are joined together with the help of a chemical bond (Dai et al., 2005) ${ }^{[16]}$.

Protein hydrolysate is a combination of amino acids which can be acquired by the hydrolysis of plant and animal protein (Sarabandi et al., 2018) ${ }^{[57]}$.

\section{Case studies related to encapsulation of peptides and protein hydrolysates}

(Yokota et al., 2012) [67] studied regarding the micro encapsulation of casein hydrolysate. Soy- lecithin was used, then the liposome preparation was done and their encapsulation efficiency was studied. With the help of photon correlation spectroscopy the average particle size was determined. The samples were also analyzed in micro calorimeter and to study the surface morphology. SEM was done, infrared spectrum was achieved with the help of FTIR and wide angle $\mathrm{x}$-ray diffraction was also conducted. The results showed that the non-cryoprotected liposome along with non-purified soy-lecithin which appeared smaller as noncryoprotected liposome with purified soy-lecithin. SEM showed huge fusions of the phospholipids vesicle did not occur in case of liposome containing cryoprotectant. It was also noted in the micrograph the presence of spherical structures and many of there were included into the amorphous mass of excess cryoprotectant. The thermal behavior of liposomal system with non-purified soy-lecithin for lyophilized liposome was seen in absence of casein hydrolysates. FTIR depicted the peak of the frequency range between $1650-1100 \mathrm{~cm}^{-1}$ and X-ray diffraction showed all the structures were completely amorphous. Thus, it was concluded that liposome produced with non-purified soy lecithin can be lyophilized by the help of sucrose and trehalose. SEM did not show any kind of fusion structures and by using DSC, the thermal analysis revealed exothermic transition in the samples which did not contained casein hydrolysate.

\section{Conclusion}

Microencapsulation is an art as well as a science with the help of which one can encapsulate wide variety of substances into a capsule and protect it against nutritional losses and surrounding environmental factors. It can be done with the help of different techniques such as spray drying, extrusion, spray chilling, etc. it is the upcoming technology with its applications in drug delivery, textile industry, beverage production, cell immobilization, etc. 
Many studies are already available to prove its adaptability and increasing demand in the market but more research is yet to be done to solve the remaining riddles related to this technology and master its types.

\section{References}

1. Abd Manaf M, Jai J, Raslan R, Subuki I, Mustapa AN. Microencapsulation methods of volatile essential oils-a review. In Advanced Materials Research 2015;1113:679683. Trans Tech Publications Ltd.

2. Araújo JMA. In Química de alimentos: Teoria e pratica (7 ed.). Viçosa, MG: Editora UFV 2019.

3. Ayoub A, Sood M, Singh J, Bandral JD, Gupta N, Bhat A. Microencapsulation 2019.

4. Bakry AM, Abbas S, Ali B, Majeed H, Abouelwafa MY, Mousa A, et al. Microencapsulation of Oils: A Comprehensive Review of Benefits, Techniques, and Applications. Comprehensive Reviews in Food Science and Food Safety, 2016;15(1):143-182.

5. Ballesteros LF, Ramirez MJ, Orrego CE, Teixeira JA, Mussatto SI. Encapsulation of antioxidant phenolic compounds extracted from spent coffee grounds by freeze-drying and spray-drying using different coating materials. Food chemistry, 2017;237:623-631.

6. Bamidele OP, Emmambux MN. Encapsulation of bioactive compounds by "extrusion" technologies: a review. Critical Reviews in Food Science and Nutrition, 2020, 1-19.

7. Betz M, Steiner B, Schantz M, Oidtmann J, Mäder K, Richling E et al. Antioxidant capacity of bilberry extract microencapsulated in whey protein hydrogels. Food Research International 2012;47(1):51-57.

8. Brauch JE, Zapata-Porras SP, Buchweitz M, Aschoff JK, Carle R. Jagua blue derived from genipa americana L. fruit: A natural alternative to commonly used blue food colorants? Food Research International 2016;89:391-398.

9. Cai K, Hu D, Lei B, Zhao H, Pan W, Song B. Determination of carbohydrates in tobacco by pressurized liquid extraction combined with a novel ultrasoundassisted dispersive liquid-liquid microextraction method. Analytica Chimica Acta, 2015;882:90-100.

10. Carvalho IT, Estevinho BN, Santos L. Application of microencapsulated essential oils in cosmetic and personal health care products - A Review. International Journal of Cosmetic Science 2015;38:109-119.

11. Casanova F, Santos L. Encapsulation of cosmetic active ingredients for topical application - a review. Journal of Microencapsulation, 2015;1, 17.

12. Chen MJ, Chen KN. Applications of probiotic encapsulation in dairy products. Encapsulation and controlled release technologies in food systems 2007;83112.

13. Codex Alimentarius Commission. Position paper on zearalenone. Joint Fao/Who Food Standards Programme, Codex Committee on food additives and contaminants. Thirty-second Session. Beijing, People's Republic of China, 2000, 20e24. Rome: CX/FAC 00/19

14. Cook MT, Tzortzis G, Charalampopoulos D, Khutoryanskiy VV. Microencapsulation of probiotics for gastrointestinal delivery. Journal of controlled release 2012;162(1):56-67.

15. Czyż K, Bodkowski R, Herbinger G, Librowski T. Omega-3 fatty acids and their role in central nervous system-a review. Current medicinal chemistry
2016;23(8):816-831.

16. Dai C, Wang B, Zhao H. Microencapsulation peptide and protein drugs delivery system. Colloids and Surfaces B: Biointerfaces 2005;41(2, 3):117-120.

17. Damodaran S, Parkin KL, Fennema OR. In Química de Alimentos de Fennema. 5. Porto Alegre: Artmed 2018.

18. Desai NM, Haware DJ, Basavaraj K, Murthy PS. Microencapsulation of antioxidant phenolic compounds from green coffee. Preparative Biochemistry and Biotechnology 2019;49(4):400-406.

19. do Amaral PHR, Andrade PL, de Conto LC. Microencapsulation and Its Uses in Food Science and Technology: A. Microencapsulation: Processes, Technologies and Industrial Applications 2019, 93.

20. Dror Y, Kuhn J, Avrahami R, Zussman E. Encapsulation of enzymes in biodegradable tubular structures. Macromolecules 2008;41(12):4187-4192.

21. Ersus S, Yurdagel U. Microencapsulation of anthocyanin pigments of black carrot (Daucus carota L.) by spray drier. Journal of food engineering 2007;80(3):805-812.

22. Esquiavel P. Handbook on Natural Pigments in Food and Beverages 2016.

23. Fangmeier M, Lehn DN, Maciel MJ, de Souza CFV. Encapsulation of bioactive ingredients by extrusion with vibrating technology: Advantages and challenges. Food and Bioprocess Technology 2019, 1-15.

24. Flores FP, Singh RK, Kerr WL, Pegg RB, Kong F. Total phenolics content and antioxidant capacities of microencapsulated blueberry anthocyanins during in vitro digestion. Food chemistry 2014;153:272-278.

25. Gadkari PV, Balaraman M. Catechins: Sources, extraction and encapsulation: A review. Food and Bioproducts Processing 2015;93:122-138.

26. Gaonkar AG, Vasisht N, Khare AR, Sobel R. Microencapsulation in the food industry: A practical implementation guide. London: Academic Press Elsevier 2014.

27. Goyal A, Sharma V, Sihag MK, Singh AK, Arora S, Sabikhi L. Fortification of dahi (Indian yoghurt) with omega-3 fatty acids using microencapsulated flaxseed oil microcapsules. Journal of food science and technology 2016;53(5):2422-2433.

28. Higuera-Ciapara I, Felix-Valenzuela L, Goycoolea FM, Argüelles-Monal W. Microencapsulation of astaxanthin in a chitosan matrix. Carbohydrate Polymers 2004;56(1): 41-45.

29. Isailović B, Kalušević A, Žuržul N, Coelho MT, Đorđević V, Alves V et al. Microencapsulation of natural antioxidants from Pterospartum tridentatum in different alginate and inulin systems. In 6th Central European Congress On Food CEFood. 2012, 1075-1081.

30. Jafari SM. Nanoencapsulation of food bioactive ingredients: Principles and applications. London: Academic Press - Elsevier 2017.

31. Keen PH, Slater NK, Routh AF. Encapsulation of lactic acid bacteria colloidosomes. Langmuir, 2012;28(46):16007-16014.

32. Khan MG, Gauttam V, Chandel HS, Ali A, Tariq K. Development of microencapsulation: A review of literature. Int. J. Sci. Stud 2016;5:264-268.

33. Khan PFKA, Rohit P, Pave AC, Sanap MD, Guajarati NA, Rane BR et al. A REVIEW ON MICROENCAPSULATION. Pharma Science Monitor, 2015;6(2). 
34. Khandbahale SV. Microencapsulation-A novel approach in drug delivery: a review. Asian Journal of Research in Pharmaceutical Science 2020;10(1):39-50.

35. Kilicay E, Karahaliloglu Z, Hazer B, Tekin IÖ, Denkbas EB. Concanavaline A conjugated bacterial polyesterbased PHBHHx nanoparticles loaded with curcumin for breast cancer therapy. Journal of Microencapsulation 2016;2048:1-12.

36. Koupantsis T, Pavlidou E, Paraskevopoulou A. Flavour encapsulation in milk proteins-CMC coacervate-type complexes. Food Hydrocolloids 2014;37:134-142.

37. Kumar KS, Tejbe SK, Banu S, Lakshmi PN, Bhowmik D. Microencapsulation technology. Indian Journal of Research in Pharmacy and Biotechnology 2013;1(3):324.

38. Li YO, González VPD, Diosady LL. Microencapsulation of vitamins, minerals, and nutraceuticals for food applications. In Microencapsulation in the Food Industry Academic Press, 2014, 501-522.

39. Livney YD. Milk proteins as vehicles for bioactives. Current opinion in colloid \& interface science 2010;15(1, 2):73-83.

40. Martín MJ, Lara-Villoslada F, Ruiz MA, Morales ME. Microencapsulation of bacteria: A review of different technologies and their impact on the probiotic effects. Innovative Food Science \& Emerging Technologies 2015;27:15-25.

41. Neha K, Haider MR, Pathak A, Yar MS. Medicinal prospects of antioxidants: A review. European journal of medicinal chemistry, 2019;178:687-704.

42. Neri-Numa IA, Pessoa MG, Paulino BN, Pastore GM. Genipin: A natural blue pigment for food and health purposes. Trends in Food Science \& Technology 2017;67:271-279

43. Ot' alora MC, Carriazo JG, Iturriaga L, Nazareno MA, Osorio C. Microencapsulation of betalains obtained from cactus fruit (Opuntia ficus-indica) by spray drying using cactus cladode mucilage and maltodextrin as encapsulating agents. Food Chemistry 2015;187:174-181.

44. Ozkan GP, Franco G, De Marco I, Xiao J, Capanoglu E. A review of microencapsulation methods for food antioxidants: Principles, advantages, drawbacks and applications. Food Chemistry 2019;272:494-506.

45. Paulo F, Santos L. Design of experiments for microencapsulation applications: A review. Materials Science and Engineering: C 2017;77:1327-1340.

46. Peanparkdee M, Iwamoto S, Yamauchi R. Microencapsulation: a review of applications in the food and pharmaceutical industries. Reviews in Agricultural Science 2016;4:56-65.

47. Porrarud S, Pranee A. Microencapsulation of Znchlorophyll pigment from Pandan leaf by spray drying and its characteristic. International Food Research Journal 2010;17:1031-1042.

48. Rascon MP, Beristain CI, García HS, Salgado MA. Carotenoid retention and storage stability of spray-dried encapsulated paprika oleoresin using gum Arabic and soy protein isolate as wall materials. LWT - Food Science and Technology 2011;44:549-557.

49. Ribeiro JS, Veloso CM. Microencapsulation of natural dyes with biopolymers for application in food: A review. Food Hydrocolloids 2020, 106374.

50. Robert Canales P, Gorena T, Romero N, Sepulveda E, Chavez J, Sáenz Hernández CL. Encapsulation of polyphenols and anthocyanins from pomegranate (Punica granatum) by spray drying 2010 .

51. Robert P, Torres V, García P, Vergara C, Sáenz C. The encapsulation of purple cactus pear (Opuntia ficus-indica) pulp by using polysaccharide-proteins as encapsulating agents. LWT-Food Science and Technology 2015;60(2):1039-1045.

52. Robinson PK. Enzymes: principles and biotechnological applications. Essays in biochemistry 2015;59:1-41.

53. Rodriguez-Amaya DB. Natural food pigments and colorants. Current Opinion in Food Science 2016;7:20-26

54. Rodriguez-Amaya DB. Update on natural food pigments - a mini-review on carotenoids, anthocyanins, and betalains. Food Research International 2019;124:200205.

55. Rosa JR, Nunes GL, Motta MH, Fortes JP, Weis GCC, Hecktheuer LHR et al. Microencapsulation of anthocyanin compounds extracted from blueberry (Vaccinium spp.) by spray drying: Characterization, stability and simulated gastrointestinal conditions. Food Hydrocolloids 2019;89:742-748.

56. San Miguel-Chávez R. Phenolic antioxidant capacity: A review of the state of the art. Phenolic CompoundsBiological Activity 2017.

57. Sarabandi K, Mahoonak AS, Hamishekar H, Ghorbani M, Jafari SM. Microencapsulation of casein hydrolysates: Physicochemical, antioxidant and microstructure properties. Journal of Food Engineering 2018;237:86-95.

58. Suganya V, Anuradha V. Microencapsulation and nanoencapsulation: a review. International Journal of Pharmaceutical and Clinical Research 2017;9(3):233239.

59. Sulu E, Biswas CS, Stadler FJ, Hazer B. Synthesis, characterization, and drug release properties of macroporous dual stimuli responsive stereo regular nanocomposites gels of poly(N-isopropylacrylamide) and graphene oxide. Journal of Porous Materials 2016

60. Timilsena YP, Akanbi TO, Khalid N, Adhikari B, Barrow CJ. Complex coacervation: Principles, mechanisms and applications in microencapsulation. International journal of biological macromolecules 2019;121: 1276-1286.

61. Tuan PM, Anh HTV, Cam LTH, Chi VNQ, Oanh DTB, Khue DB et al. Extraction and encapsulation of polyphenols from guava leaves. Annals Food Science and Technology 2016.

62. Wang B, Sheng H, Shi Y, Hu W, Hong N, Zeng W et al. Recent advances for microencapsulation of flame retardant. Polymer degradation and stability, 2015;113:96-109.

63. Wang JX, Guo W, Xiong K, Wang SN. Review of aerospace-oriented spray cooling technology. Progress in Aerospace Sciences 2020;116:100635.

64. Wazarkar K, Patil D, Rane A, Balgude D, Kathalewar M, Sabnis A. Microencapsulation: an emerging technique in the modern coating industry. RSC advances 2016;6(108), 106964-106979.

65. Wilkowska A, Ambroziak W, Adamiec J, Czyżowska A. Preservation of antioxidant activity and polyphenols in chokeberry juice and wine with the use of microencapsulation. Journal of Food Processing and Preservation, 2017;41(3):e12924.

66. Wilson N, Shah NP. Microencapsulation of vitamins. ASEAN Food Journal 2007;14(1):1.

67. Yokota D, Moraes M, Pinho S. Characterization of 
lyophilized liposomes produced with non-purified soy lecithin: a case study of casein hydrolysate microencapsulation. Brazilian Journal of Chemical Engineering, 2012;29(2):325-335.

68. Zanoni F, Primiterra M, Angeli N, Zoccatelli G. Microencapsulation by spray-drying of polyphenols extracted from red chicory and red cabbage: Effects on stability and color properties. Food chemistry 2020;307:125535.

69. Zhao X, Yin Z, Zhang B. Experimental study on transient heat transfer characteristics of intermittent spray cooling. Experimental Heat Transfer 2020;33(7):613-632.

70. Zhu GY, Xiao ZB, Zhou RJ, Yi FP. Fragrance and flavor microencapsulation technology. In Advanced Materials Research Trans Tech Publications Ltd 2012;535:440-445. 